\title{
Water Ingress Failure Analysis of Whistler II Unit
}

\author{
by Andrew J Bayba
}

ARL-TN-0623

August 2014

Approved for public release; distribution unlimited. 


\section{NOTICES}

\section{Disclaimers}

The findings in this report are not to be construed as an official Department of the Army position unless so designated by other authorized documents.

Citation of manufacturer's or trade names does not constitute an official endorsement or approval of the use thereof.

Destroy this report when it is no longer needed. Do not return it to the originator. 


\title{
Army Research Laboratory
}

Adelphi, MD 20783-1138

ARL-TN-0623

August 2014

\section{Water Ingress Failure Analysis of Whistler II Unit}

\author{
Andrew J Bayba
}

Sensors and Electron Devices Directorate, ARL 


\section{REPORT DOCUMENTATION PAGE}

Public reporting burden for this collection of information is estimated to average 1 hour per response, including the time for reviewing instructions, searching existing data sources, gathering and maintaining the data needed, and completing and reviewing the collection information. Send comments regarding this burden estimate or any other aspect of this collection of information, including suggestions for reducing the burden, to Department of Defense, Washington Headquarters Services, Directorate for Information Operations and Reports (0704-0188), 1215 Jefferson Davis Highway, Suite 1204, Arlington, VA 22202-4302. Respondents should be aware that notwithstanding any other provision of law, no person shall be subject to any penalty for failing to comply with a collection of information if it does not display a currently valid OMB control number.

PLEASE DO NOT RETURN YOUR FORM TO THE ABOVE ADDRESS.

\begin{tabular}{|c|c|c|}
\hline $\begin{array}{l}\text { 1. REPORT DATE (DD-MM-YYYY) } \\
\text { August } 2014\end{array}$ & $\begin{array}{l}\text { 2. REPORT TYPE } \\
\text { Final }\end{array}$ & $\begin{array}{l}\text { 3. DATES COVERED (From - To) } \\
02 / 1014 \text { to } 05 / 2014\end{array}$ \\
\hline \multirow{4}{*}{\multicolumn{2}{|c|}{$\begin{array}{l}\text { 4. TITLE AND SUBTITLE } \\
\text { Water Ingress Failure Analysis of Whistler II Unit }\end{array}$}} & 5a. CONTRACT NUMBER \\
\hline & & \\
\hline & & 5b. GRANT NUMBER \\
\hline & & 5c. PROGRAM ELEMENT NUMBER \\
\hline \multirow{4}{*}{\multicolumn{2}{|c|}{$\begin{array}{l}\text { 6. AUTHOR(S) } \\
\text { Andrew J Bayba }\end{array}$}} & 5d. PROJECT NUMBER \\
\hline & & R.0005942.1.3 \\
\hline & & 5e. TASK NUMBER \\
\hline & & 5f. WORK UNIT NUMBER \\
\hline \multicolumn{2}{|c|}{$\begin{array}{l}\text { 7. PERFORMING ORGANIZATION NAME(S) AND ADDRESS(ES) } \\
\text { U.S. Army Research Laboratory } \\
\text { ATTN: RDRL-SER-E } \\
\text { 2800 Powder Mill Road } \\
\text { Adelphi, MD 20783-1138 }\end{array}$} & $\begin{array}{l}\text { 8. PERFORMING ORGANIZATION } \\
\text { REPORT NUMBER } \\
\text { ARL-TN-0623 }\end{array}$ \\
\hline \multirow{2}{*}{\multicolumn{2}{|c|}{ 9. SPONSORING/MONITORING AGENCY NAME(S) AND ADDRESS(ES) }} & 10. SPONSOR/MONITOR'S ACRONYM(S) \\
\hline & & $\begin{array}{l}\text { 11. SPONSOR/MONITOR'S REPORT } \\
\text { NUMBER(S) }\end{array}$ \\
\hline
\end{tabular}

\section{DISTRIBUTION/AVAILABILITY STATEMENT}

Approved for public release; distribution unlimited.

\section{SUPPLEMENTARY NOTES}

\section{ABSTRACT}

Due to a water ingress failure of one of the Whistler II Units during testing by the Army Evaluation and Testing Center (ATEC), we examined the failed unit and performed testing at the US Army Research Laboratory (ARL) to ascertain the mode of failure. Our primary interest was to determine potential flaws or vulnerabilities in the design. We discovered that there is no reason to believe that the unit would have failed if it had been tested in its proper configuration; specifically, we have concluded from our testing that the unit must have had its audio adaptor removed during the ATEC testing and that the battery door was likely not fully secured. Our results also indicate that the audio connector and battery door latching design present vulnerabilities that should be addressed to reduce the risk of water ingress.

\section{SUBJECT TERMS}

Failure Analysis, Water Ingress, Ingress Protection, Rain Test

\begin{tabular}{|l|l|l|l|l|l|}
\hline \multicolumn{2}{|l|}{$\begin{array}{l}\text { 16. SECURITY CLASSIFICATION OF: } \\
\text { A. Report }\end{array}$} & $\begin{array}{l}\text { 17. LIMITATION } \\
\text { OF } \\
\text { ABSTRACT } \\
\text { Unclassified }\end{array}$ & $\begin{array}{l}\text { 18. NUMBER } \\
\text { OF } \\
\text { PAGES }\end{array}$ & $\begin{array}{l}\text { 19a. NAME OF RESPONSIBLE PERSON } \\
\text { Andrew J Bayba }\end{array}$ \\
\cline { 1 - 2 } & Unclassified & $\begin{array}{l}\text { c. THIS PAGE } \\
\text { Unclassified }\end{array}$ & UU & 16 & $\begin{array}{l}\text { 19b. TELEPHONE NUMBER (Include area code) } \\
(301) 394-0440\end{array}$ \\
\hline
\end{tabular}




\section{Contents}

List of Figures $\quad$ iv

$\begin{array}{lr}\text { 1. Introduction } & 1\end{array}$

2. Observations of the Failed Unit (Unit 6) 1

3. ARL Ingress Testing After the ATEC Test 3

$\begin{array}{lr}\text { 4. Synopsis } & 8\end{array}$

$\begin{array}{lr}\text { 5. Conclusion and Recommendations } & 8\end{array}$

$\begin{array}{ll}\text { Distribution List } & 10\end{array}$ 


\section{List of Figures}

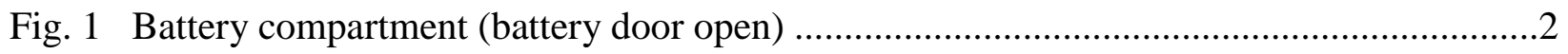

Fig. 2 Electronics compartment (electronics removed) ................................................... 3

Fig. 3 External view, showing interface components .....................................................4

Fig. 4 Configuration for Excursion Tests (audio adaptor detached---not normal

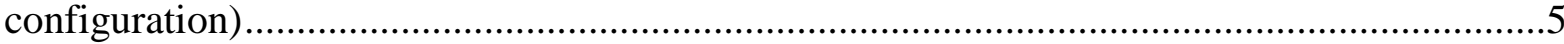




\section{Introduction}

Environmental testing was performed by the Army Testing and Evaluation Center (ATEC) at Yuma Proving Ground (YPG) on the Whistler System Version II in the winter of 2013-2014. One of the tests was a rain test, in which the units were subject to 4 in of rain per hour for $30 \mathrm{~min}$ (assuming the original ATEC test plan, as relayed to the US Army Research Laboratory (ARL), was followed). One of the three units tested failed - that is, it did not operate properly after subjection to the rain environment. ARL did not expect any of the units to fail this test; consequently, we performed an investigation and further testing of the failed unit to ascertain its mode of failure so that any issues could be remedied.

\section{Observations of the Failed Unit (Unit 6)}

We found significant moisture present in the battery compartment (Fig. 1).

a. The O-ring seal was intact.

b. White powdery residue was present on aluminum surfaces consistent with aluminum corrosion. All aluminum surfaces were chromate conversion coated and should not have been subject to corrosion with exposure to ordinary rain water. The batteries were highly corroded, and some chemicals likely leaked out. Due to the inherent corrosive nature of these chemicals, there dispersion in the water that was present is the most likely explanation of the high level of corrosion seen on the aluminum. Also, the possible shorting of the batteries through the moisture on the compartment surfaces could have aggravated the corrosion. A final contributor could be that the passivation process was done poorly. 


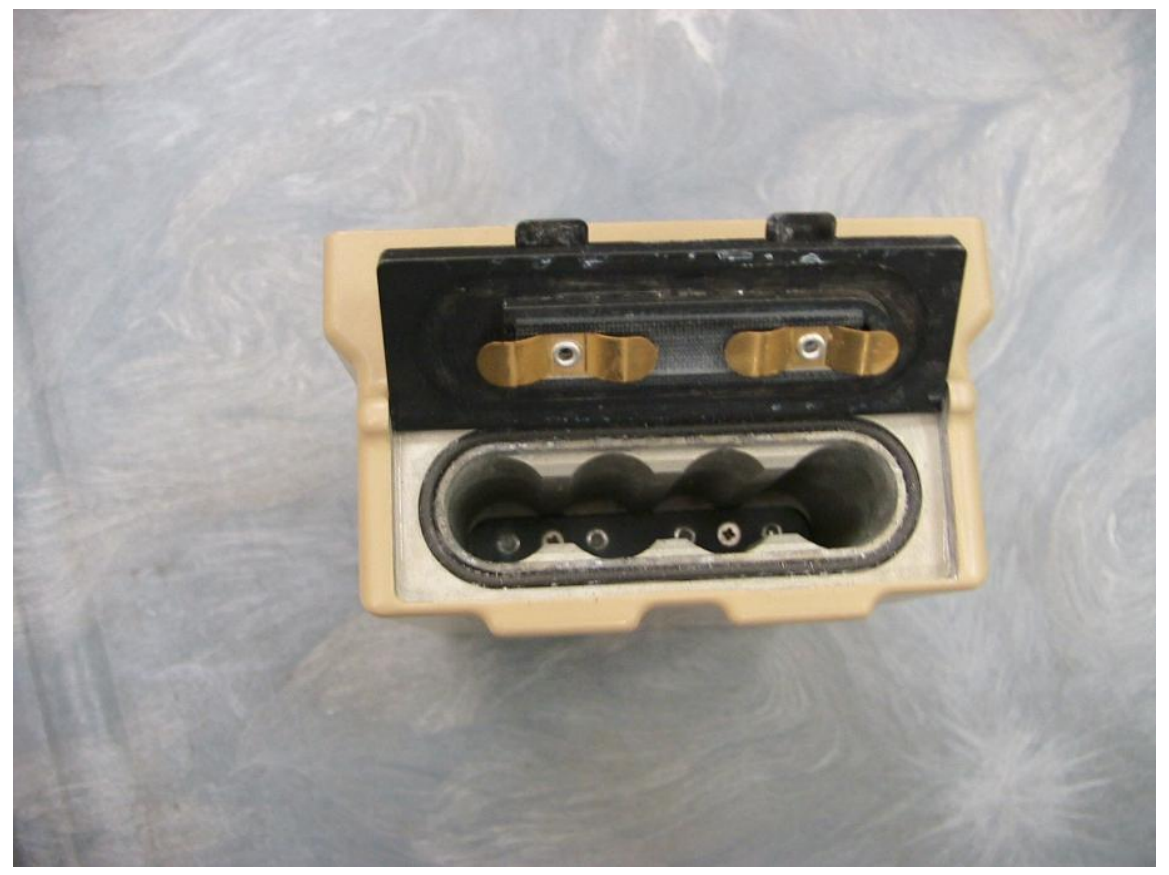

Fig. 1 Battery compartment (battery door open)

We found significant moisture present in the electronics compartment (Fig. 2).

a. The O-ring seal was intact.

b. White residue was present on many of the solder joints. Per Art Harrison, this is consistent with exposure of solder flux to moisture.

c. Corrosion was present in the cavity. Most, if not all, of the corrosion present in the electronics compartment appears to be attributable to water, possibly ionized, present at dissimilar metal interfaces, thus forming a galvanic reaction. White powdery residue was present on some of the aluminum surfaces consistent with aluminum corrosion; however, it was not as prolific as in the battery compartment and in most cases could be wiped off without evidence of damage to the surface, indicating that this residue was likely from localized sources and redeposited on noncorroded faces. Orange-Brown residue was present on the star washers of both switches, consistent with corrosion of steel (rust). The material of the star washers is zinc-plated steel/chromate conversion coated. Corrosion of the star washers was greater than would be expected by normal rain water at normal temperatures. Limited orange-brown residue was present on the steel shield compartment on the audio board, consistent with the corrosion of steel (rust). 


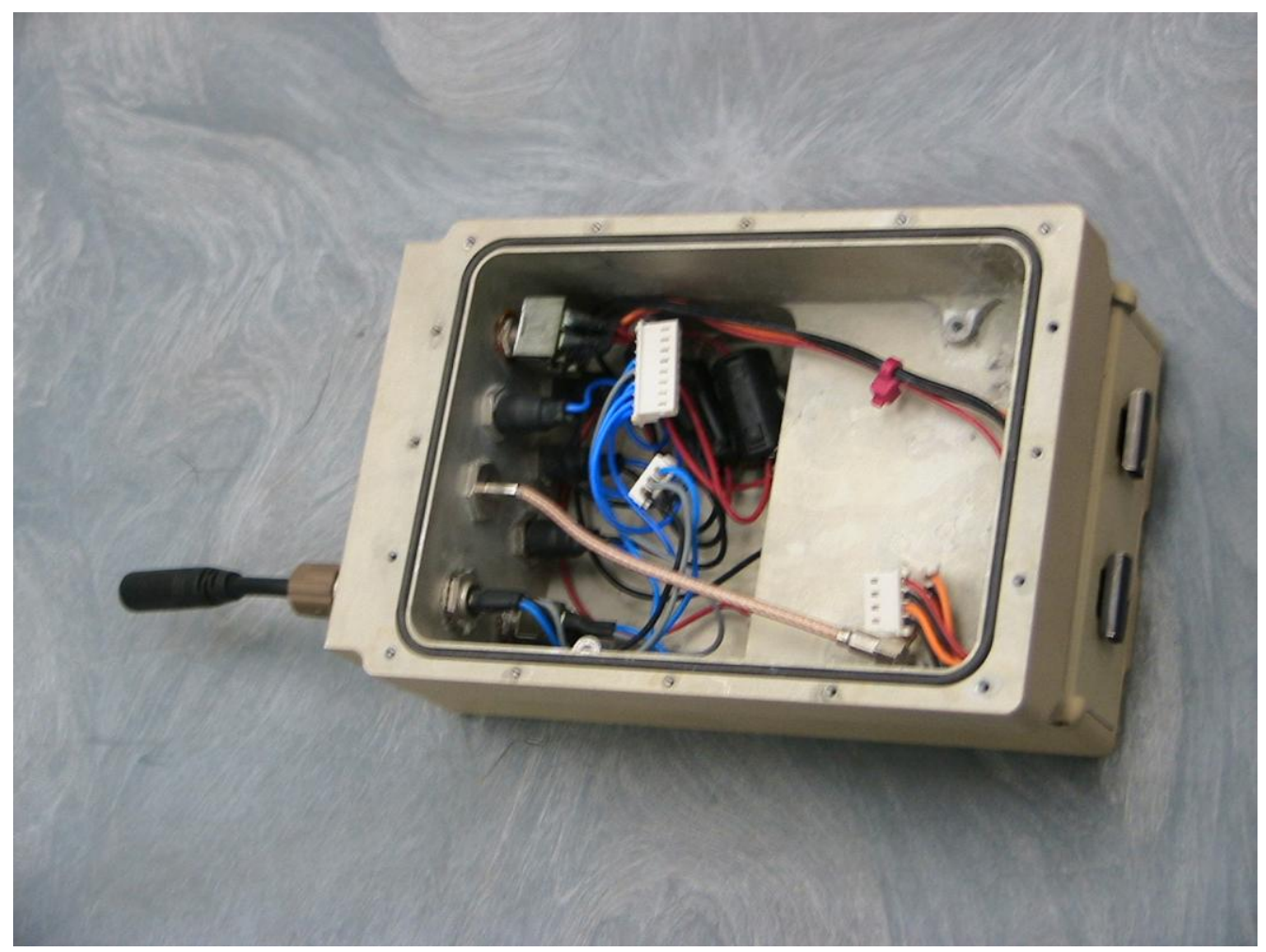

Fig. 2 Electronics compartment (electronics removed)

The sealant that was applied at the wire feed-throughs and screw holes between the battery compartment and electronics compartment was intact (Dow Corning 3145 RTV).

The on/off switch was not extended out of box as much as normal (leaving a lack of snugness in the boot to switch bat fit); this would only become an ingress problem if the boot were to tear. The boot was not damaged.

Tightness of the accessible interface components was examined by applying a small amount of torque to their retaining nuts in the "tightening direction," such that tightness could be evaluated without actually altering the tightness. This included the power light-emitting diode (LED), the on/off switch, the antenna connector, and the audio connector. The power LED and the on/off switch retaining nuts were not very tight; however, they were not "loose" and were believed to be tight enough to compress the associated gaskets to prevent ingress.

\section{ARL Ingress Testing After the ATEC Test}

There were three rounds of testing to identify the cause of leakage into the unit. The first were Initial Tests, first assessing the susceptibility of leakage on a second unit prior to the return of the failed unit and then on the failed unit to see if any mode of leakage could be easily identified. Secondly, the failed unit was put through a series of progressively more demanding tests to 
attempt to identify the leakage source; these are designated as the Primary Tests. The first Primary Test was deemed equivalent to the worst case of the ATEC Rain Test. The final Primary Test was complete submersion in a moderate depth of water-substantially more severe than the rain test. Finally, the unit was subjected to a series of tests designated as Excursion Tests. The term excursion is used since the unit was not tested in its normal configuration. In the Excursion Tests, the audio adaptor cable was removed, as the initial and primary tests showed no leakage into the unit and because we suppose that this could have been a condition in which ATEC tested the unit(s); compare Fig. 3 and 4, with Fig. 3 being the normal configuration. Again, all the following tests are on Unit 6, the failed unit, except Initial Test 1.

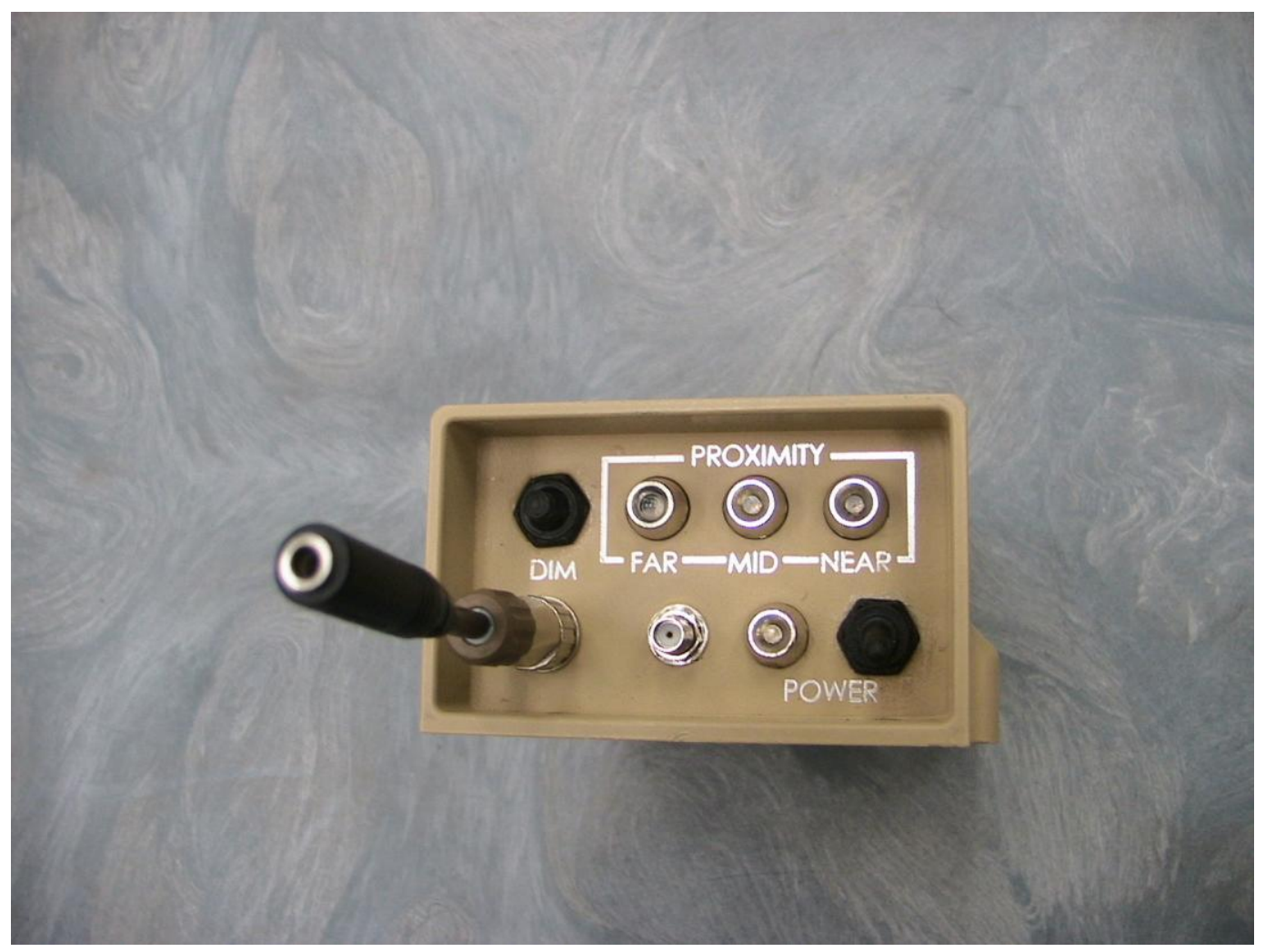

Fig. 3 External view, showing interface components 


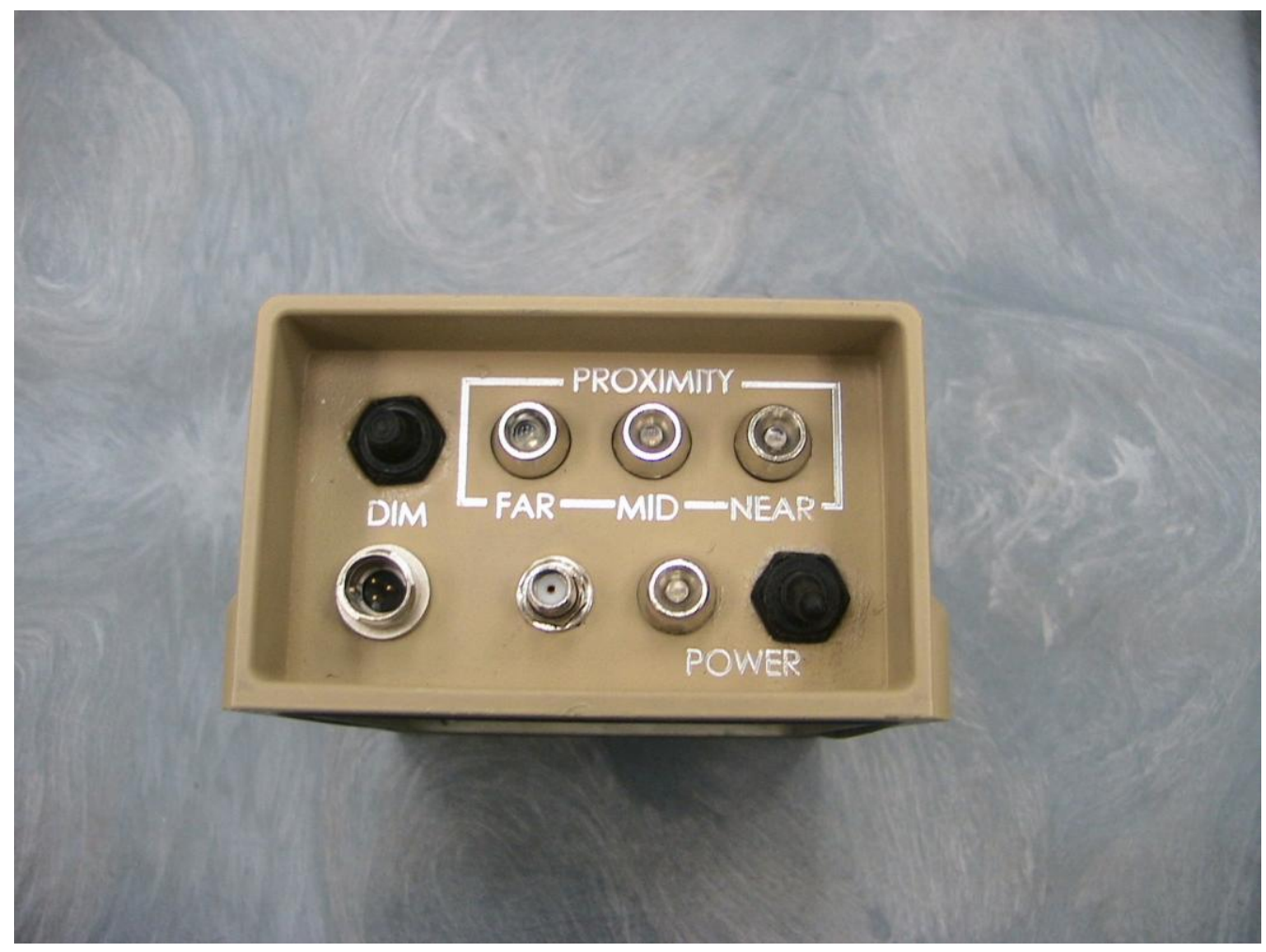

Fig. 4 Configuration for Excursion Tests (audio adaptor detached---not normal configuration)

a. Initial Test 1. Unit 11 had performance issues during the cold testing; and since it would be taken out of any further formal testing or field use, it was deemed reasonable to perform a simple water leak test on it. The testing occurred immediately after notification that a unit (unit 6) had failed the rain testing at YPG ATEC on February 26, 2014. Failure at the battery and electronics compartment openings was deemed highly unlikely since these openings are sealed by O-rings, and that there would be no build up of water at these locations. Leakage at the control/interface panel is more likely because there would be a build-up of up to 5/8 in of water at the surface and because the interface components are rated at a lower ingress protection (particularly the on/off switch and the dim switch [IP 65]). The test consisted of filling the $5 / 8$ in deep recess with tap water, examining for bubble formation, and monitoring for power and LED functionality. The water was allowed to stand for $30 \mathrm{~min}$, consistent with the length of the ATEC rain test (based on ATECs proposed test plan). The result was that there was no bubble formation, nor was there any loss of electrical functionality.

b. Initial Test 2. After its return from ATEC and examined as described above, Unit 6 was completely dried and then fully immersed in 6 in of water and monitored for $5 \mathrm{~min}$. There was no expulsion of bubbles from the unit (which would be required if there was a leak). The unit was opened after the test; no moisture could be identified in either the battery compartment or the electronics cavity. 


\section{c. Primary Test 1a. Rain Test Equivalent - Normal Configuration (see Fig. 3)}

The top of the unit was filled with tap water and carefully examined for bubble formation for $30 \mathrm{~min}$. None could be detected. This amount of water-5/8 in - would apply a very low pressure; however, it is the worst case in the ATEC rain test. After removing the water, the electrical compartment cover was removed and there was no moisture present in the electrical compartment. As expected, there was no moisture present in the battery compartment (since there was no water in the electrical compartment and there was no significant external exposure to water at the battery compartment door).

\section{d. Primary Test 1b. Minimal Submersion - Normal Configuration}

Unit 6 was fully submerged in tap water horizontally such that the upper face (the cover plate face) was $11 / 2$ in below the water surface, and the lower face was $33 / 4$ in below the water surface. The unit was immersed for $30 \mathrm{~min}$. This case is significantly more demanding than the 30 min of rain in ATEC's Test Plan. After the unit was removed from the water, the electronics cover plate was removed and the battery compartment opened; there was no moisture present in either compartment.

\section{e. Primary Test 1c. Moderate Submersion - Normal Configuration}

The entire unit was submerged in tap water with the interface components facing up, such that the water depth at the component interface was 8 in, thus increasing the water pressure. The base of the unit (battery door area) was at 13 in water depth. This scenario is much more severe than the ATEC Rain Test. The unit was observed for bubble formation for $45 \mathrm{~min}$. After the unit was removed from the water, the electronics cover plate was removed and the battery compartment opened; there was no moisture present in either compartment.

\section{f. Excursion Test 1a. Rain Test Equivalent - Audio Adaptor Detached}

The test procedure was identical to Primary Test 1a. The top of the unit was filled with tap water and carefully examined for bubble formation for $30 \mathrm{~min}$. No bubbles could be detected. The case was opened, and there was no moisture in the Electrical compartment. As in 1a, there was also no water in the battery compartment.

\section{g. Excursion Test 1b. Limited Submersion - Audio Adaptor Detached}

The test procedure was identical to Primary Test $1 b$.

\section{Results:}

i. Moisture was present in bottom of deepest portion of electrical compartment, but there was none on shallow portion of compartment. No leakage was found around the electrical compartment O-ring; no moisture was detected on the compartment 
wall between the O-ring and any other opening. There was no moisture apparent on the circuit boards.

ii. No water was present in the battery compartment, indicating that there was no leakage past the battery door O-ring. It also indicates that there was also no leakage through the RTV sealant between the battery and electronics compartment; however, with the limited quantity of water present, one could not definitely state that this path was absolutely watertight.

iii. All indications were that at least one of the external-to-internal interface components was not sealed properly (LEDs, switches, and connectors).

1. As stated, no moisture was apparent on the circuit boards. This is consistent with leakage through a component(s) due to the horizontal orientation of the unit in the water with the cover facing up-i.e., water would seep through the leaking component, down the compartment wall, and build on the bottom, without moisture getting on the boards or upper compartment surface.

2. The offending component(s) could not be identified in situ. Removing them individually may have identified the leaker(s); there would, however, still be some ambiguity, as the water from an elevated component could seep onto lower ones. This would also disallow any further testing, since the identical conditions could not be matched with reassembly. Instead, increased submersion testing for leak locations was performed.

\section{h. Excursion Test 1c. Moderate Submersion - Audio Adaptor Detached}

The test procedure was identical to Primary Test 1c., with the exception that the duration was only $30 \mathrm{~min}$.

i. The unit was observed for bubble formation for $30 \mathrm{~min}$. Bubbling/leaking was detected intermittently at the audio connector electrical mating interface (audio receptacle). Although intermittent, the quantity of bubbles released at each event was substantial. Note that the leak did not occur at the audio connector to bulkhead interface were the component's seal is, but "through" the connector, itself. Also of significant note, even though there was substantial water in the electrical compartment, there was no trace of water in the battery compartment; this would indicate that the RTV sealant at the holes between the two compartments did not fail, properly isolating moisture between the compartments. 


\section{Synopsis}

Inspection of Whistler II Unit 6 and water ingress testing were performed at ARL after the "Rain Test" failure at YPG performed by ATEC. By disassembling and inspecting the unit, we discovered that there was substantial moisture in both the electronics and the battery compartment. The corrosion of metals in both compartments appears excessive, and was likely due to contaminants getting in the water, possibly from the batteries, the solder flux, some other means, or some combination.

The Whistler Unit was subject to several leak tests to identify the source of the leak(s). It should be noted that all those designated as Primary Tests are at least as severe as the ATEC Rain Test, most substantially more severe. The reason for the increased severity is that no leaks could be detected in test $1 \mathrm{a}$ - the closest equivalent to the rain test that we could devise. In all of the tests with the unit in its normal configuration, there was no ingress of water. Consequently, the testing was made more severe by removing the audio cable adaptor. Only in submersion tests with the audio cable adaptor removed did a leak present itself, namely the connection interface of the audio receptacle. It is not known whether the ATEC testing had the audio cable adaptor in place or not, but it is now presumed that they did not. This may be a test of interest; however, it deviates from the unit in its normal configuration and should not be designated as a failure of the unit. It should also be noted that in the ARL testing, there was never ingress into the battery compartment, which brings into question whether the battery compartment was fully closed/latched during the ATEC testing of the unit.

\section{Conclusion and Recommendations}

We believe that there were flaws with the ATEC testing; regardless, certain vulnerabilities were discovered that should be addressed in the next Whistler design iteration. Based on our testing, we can surmise that ATEC tested the unit(s) without the audio adaptor cable in place, although this is not the normal configuration. The manufacture's specification for the audio connection is that its protection from water ingress is well above our requirements with an Ingress Protection Marking of 68, based on IEC standard 60529 when the Plug and Receptacle are mated. However, a specification for the unmated condition is not given. Although the normal configuration is that the connectors are always mated, we should consider that the Whistler unit could be exposed to the unmated condition in the field. This being the case, it is recommended that the current audio connector pair be replaced with one that clearly specifies protection from water ingress in both mated and unmated configurations. Based on our testing, we also believe that the battery door was not fully closed/latched during the ATEC testing. We now believe that the design of the 
latch could be improved such that there is no ambiguity whether the door is fully latched or not. Finally, we would like to reiterate that we believe that the Rain Test of this unit should not have been classified as a failure. 


$\begin{array}{cl}1 & \text { DEFENSE TECH INFO CTR } \\ \text { (PDF) } & \text { ATTN DTIC OCA (PDF) } \\ 2 & \text { US ARMY RSRCH LABORATORY } \\ (\mathrm{PDF}) & \begin{array}{l}\text { ATTN IMAL HRA MAIL \& RECORDS MGMT } \\ \text { ATTN RDRL CIO LL TECHL LIB }\end{array} \\ 1 & \text { GOVT PRNTG OFC } \\ (\mathrm{PDF}) & \text { ATTN A MALHOTRA } \\ 6 & \text { US ARMY RSRCH LAB } \\ \text { (PDF) } & \text { ATTN RDRL D T RUSSELL } \\ 2 & \text { ATTN RDRL SER M J CLARK } \\ \text { (HC) } & \text { ATTN RDRL SER U D MCNAMARA } \\ & \text { ATTN RDRL SER U M HIGGINS } \\ & \text { ATTN RDRL SER E A BAYBA (1 HC, 1 PC) } \\ & \text { ATTN RDRL SER E R DEL ROSARIO (1 HC, 1 PC) }\end{array}$

